\title{
Te corto, te furo e te fujo: mulheres de fé, mulheres que benzem
}

\author{
Assis Felipe Menin \\ Universidade do Estado de Santa Catarina - UDESC
}

Resumo: O artigo procura analisar as práticas de benzimento de três mulheres no interior do município de Campos Novos/SC e, com isso, através da etnografia e de seu cotidiano, compreender suas memórias, os usos do passado no presente, o significado do rito ontem e hoje, juntamente com as ações e práticas que se descortinam entre o profano e o sagrado, entre o simbólico e a fé, para um entendimento dos saberes do benzimento que transcorrem ao longo de suas experiências com o benzimento.

Palavras-chave: Benzimento; memória; mulheres. 


\title{
I cut you, I stab you, I get away: faith women, women who bless
}

\begin{abstract}
The paper analyzes the benzimento (healing prayers and rituals) practices of three women inside the municipality of Campos Novos / SC and, by studying and their ethnography and daily lives, seek to understand their memories, the past practices in the present times, the meaning of the rite yesterday and today, along with the actions and practices that are revealed between the profane and the sacred, between the symbolic and the faith, for an understanding of the knowledge of the benzimento that occur over their trajectories and sociabilities.
\end{abstract}

Keywords: Benzimento; memory; women.

\section{Se corta, se hole y huir de ti: mujeres de fe, mujeres que bendicen}

Resumen: El artículo analiza las prácticas de benzimento de tres mujeres dentro del término municipal de Campos Novos / SC y, por tanto, a través de la etnografía y su vida cotidiana, entender sus recuerdos, los usos del passado en presente, el significado del rito ayer y hoy en día, junto con las acciones y prácticas que se revelan entre lo profano y lo sagrado, entre lo simbólico y la fe, para la comprensión de los conocimientos benzimento que gastar más de sus experiencias con benzimento.

Palabras clave: Benzimento; memoria; mujeres. 
Campos Novos, em Santa Catarina, é um município de aproximadamente 35 mil habitantes, banhado pelas águas do Rio do Peixe, cuja nascente atravessa vários municípios da região do Contestado. Recebeu imigrantes teutobrasileiros e ítalo-brasileiros oriundos do estado vizinho, Rio Grande do Sul, que se fixaram na região principalmente a partir das décadas de 1920 e 1930. Também é significativa a presença da população de afro-brasileiros, que já se encontravam na região antes da imigração de descendentes europeus, e os chamados caboclos, muitos destes descendentes do povo do Contestado.

Conforme Renk (1990: 90): “Em Campos Novos-SC, houve a preocupação em explicitar por lei municipal os requisitos dos povoadores desejados: descendentes de alemães e italianos", contribuindo assim para a exclusão e estigmatização da população que já residia nesta localidade. A economia do município tem fortes características do agronegócio e, ainda, do que chamamos aqui de "práticas do Catolicismo Popular" e uma hibridização de benzimentos dos locais, os caboclos, com os outsiders, os descendentes de italianos e alemães que ali se estabeleceram. Segundo Faustino (2005: $14-23$ ):

\begin{abstract}
Esse Catolicismo das devoções populares mantinha uma relativa autonomia com respeito ao catolicismo institucional. Não havia uma imposição de padres [...] a dinâmica dessa religiosidade dispensava a presença dos representantes oficiais da Igreja gozando, assim, de ampla liberdade. [...] Para certas bênçãos ou rituais de passagem [o padre era requisitado], mas o resto da vida de fé ficava mesmo por conta dos agentes religiosos populares.
\end{abstract}

Esta forma de religiosidade é ainda intensamente praticada na cidade e nas áreas rurais do município. O tratamento das doenças e acometimentos de menor intensidade e que não necessitavam de uma consulta médica, entre a população carente do interior e do mundo rural, poderia ser facilmente realizado por uma benzedeira. Assim, a benzedeira se tornou o "médico" dos pobres, e com isso angariou um enorme prestígio social.

A pesquisa deste trabalho parte da experiência do próprio autor e de suas memórias de infância, durante a infância convivi com rituais, benzimentos e práticas de cura e rituais motivados por devoção e crenças no benzimento e que descreve-se a prática do benzimento destas mulheres através deste artigo. Segundo Maurice Halbwachs (1990: 72), “temos, desde a infância em contato com os adultos, muitos meios de encontrar e precisar muitas lembranças que, sem estes, as teríamos, em sua totalidade ou em parte, esquecido rapidamente".

As recordações constituem a formação de uma infância que se reproduz por narração e permitem reviver e ressignificar aquilo que foi experienciado trajetórias de saberes, alegrias, tristezas, em uma constante disputa de identidade e memória. Essas memórias, identidades e saberes são trabalhados 
com os diferentes tempos e espaços das benzedeiras, já que a prática do benzimento atravessa toda a trajetória de vida destas mulheres.

O recorte temporal deste artigo são as ações de benzedeiras no início e decorrer do século XXI, mas sem estabelecer hierarquias temporais, e sim experiências que são transmitidas através dos espaços de que se pode recordar da história de vida e do benzimento.

Se a história é pensada e praticada a partir do presente, as questões e indagações são intermediadas por temas do passado e por fontes do passado, mas que, neste artigo, tratam de uma abordagem de experiências entre o passado e o presente. Segundo Koselleck, as histórias são construídas por espaços de experiência e pelas "expectativas das pessoas que atuam ou que sofrem" (2006: 306). A história das experiências de vida destas mulheres e de seu cotidiano se tornou uma crítica às religiões majoritárias e às representações de uma cultura dominante. Segundo Dias (1998: 231),

[...] É preciso ter em mente que o próprio conceito de cotidiano também tem sua própria historicidade e, se no mundo contemporâneo ganhou um sentido estratégico de homogeneização de costumes e hábitos, é precisamente porque passou a ocupar o plano ideológico que tinham, no século passado, as instituições nacionais [...].

Durante o processo de pesquisa com as três mulheres benzedeiras1, por se tratar de suas vidas, intimidade e experiências, optou-se pela história oral de vida, ainda que, durante as entrevistas, tenha-se intercalado com a história das benzeduras mais especificamente, portanto, história oral temática. Duas destas mulheres são de origem ítalo-brasileira; e a outra, afro-ítalo-brasileira. Elas têm 62, 78 e 86 anos, e todas se conhecem na comunidade e são indicadas a outras benzedeiras em caso de impossibilidade do benzimento. Uma delas estudou até a $4^{\mathrm{a}}$ série e as duas outras não têm escolarização2. Portanto, as mulheres entrevistadas selecionada supera delimitações de um grupo étnico definido ou de instrução, circulando entre afrodescendentes e ítalo-brasileiros. Isso, juntamente com a metodologia da história oral, contribuiu para o descobrir e o fazer de suas práticas cotidianas de benzimento, bem como de suas artes de fazer, e suas táticas e subterfúgios de resistir.

Durante a pesquisa com as benzedeiras pediram para que seus nomes não fossem divulgados, receosas das práticas por elas realizadas. O que é compreensível, pois durante tempo a condenação de suas práticas, da Inquisição até aos dias de hoje. Na própria sociedade em que estão inseridas, a partir de valores culturais e também baseados em cristãos, já que, durante suas trajetórias, as benzedeiras relataram ter encontrado resistência por parte de grupos religiosos, não somente de católicos e céticos, quanto ao benzimento.

1 O método utilizado para a realização das entrevistas foi o da História Oral Temática e também o da História Oral de vida. A História Oral Temática foi mais utilizada por ser considerada a narrativa de fatos e "modos de fazer" o benzimento. As entrevistas foram realizadas em outubro de 2014, e os nomes das benzedeiras não são reais, a fim de preservar suas identidades. Além disso, a oralidade da fala das mulheres entrevistadas foi preservada, na medida do possível, mantendo-se as principais características do dialeto talian, falado entre os descendentes de italianos no Brasil. 2 Antes de ligar o gravador, D. Generosa relatou que, certa vez, quando informou a seu pai o desejo de estudar, este lhe deu a seguinte resposta: "Menina não precisa ir para escola, menino sim!" Esta é uma característica bem comum entre famílias rurais, principalmente neste caso, em que a família de D. Generosa é de origem italiana. Entre os descendentes de italianos do sul do Brasil, a mulher ganhava um dote quando do matrimônio, que era basicamente tecido, roupas e equipamentos para casa; o homem tinha a herança da terra, a ele se destinava a continuação da propriedade agrícola (Bloemer, 2000). 
Embora não estivessem diretamente ligadas a grupos religiosos estas mulheres relataram haver sofrido discriminação, em algum momento de suas vidas, seja da Igreja Católica, Evangélica e até dos descrentes nas práticas de benzimento.

Mas como pode ser considerada a prática do benzimento? Partindo dos pressupostos de Bahia:

\begin{abstract}
As benzedeiras são consideradas um misto de médicas e sacerdotisas. Não cobram dinheiro pelo que fazem, em geral recebem em troca produtos e alimentos, que significam uma forma de retribuição a uma dádiva. A benção que protege e cura os males da sociedade é uma dádiva que assegura os laços e a unidade do grupo. (2011: 273).
\end{abstract}

É uma das várias atividades e das muitas práticas antigas do Catolicismo Popular brasileiro, cujas principais especialistas são mulheres. Pode-se dizer que essa realidade se confirma em Campos Novos, visto que, tal como comprovou a pesquisa de campo deste trabalho, não se encontrou nenhum homem em Campos Novos que realizasse o benzimento. Isso não significa dizer que é uma prática exclusiva de mulheres, pois, conforme os estudos sobre o caso - Bahia (2011) e Maluf (1993) -, benzedores homens atuam nesta atividade ainda presente na sociedade contemporânea brasileira, embora a presença das mulheres seja predominante no âmbito do benzimento. São elas que conhecem as doenças e males que acometem o paciente e práticas do dom de benzer e os gestos capazes de curar o paciente e afastar o mal.

Quem é essa mulher benzedeira? O que ela faz? Segundo Geleski (2014), que estudou as benzedeiras da Ilha de Santa Catarina, sua imagem é a de uma mulher que conforta os que creem em suas rezas e bênçãos, afasta os males, e tem o dom de curá-los e confortar quem as procura. Com o manuseio de linhas, pratos, garrafas, água, velas e rosário, bem como signos e símbolos da Igreja Católica, estabelecem a aproximação maior com santos que invocam. Entre elas não existe uma relação de poder; há, sim, uma indicação quando seu campo de atuação não corresponde ao problema do paciente. $\mathrm{O}$ benzimento, seus fazeres e saberes são uma forma que as mulheres rurais do município de Campos Novos encontraram para a reinvenção do saber feminino.

Diferentemente dos estudos de Cascaes (2003) e Maluf (1993) sobre as benzedeiras de Florianópolis, que revelam tensões entre benzedeiras e a bruxa, no estudo reportado neste artigo, não é buscada essas tensões, embora ocorram no imaginário da comunidade, não é objeto de pesquisa, aqui são buscados os significados do benzimento na esfera do simbólico e das trocas sociais.

A relação destas mulheres do campesinato com a natureza foi e é próxima e as condições cotidianas de saúde e religiosidades estão presentes. Duas entrevistadas são viúvas e a outra, casada. Em suas casas modestas as práticas não têm horário para começar. Suas práticas diárias para enfrentar os problemas que afligem os moradores fazem deste catolicismo popular uma vertente periférica - a do catolicismo popular3 no Planalto e Meio-Oeste

3 Para Welter (2007) o catolicismo popular ou ainda religião popular pode ser definido como uma forma de expressar a religião a partir dos próprios indivíduos, e que seguem mecanismos alheios à prática da religião católica, por exemplo. Ainda segundo Welter, toda religião pode ser caracterizada como popular, o que diferencia é o espaço sociocultural 
Catarinense -, na qual se misturam práticas de benzimento dos afro-brasileiros com as dos portugueses, as de ascendência ítalo-brasileira e as dos moradores que já residiam na região oeste e meio-oeste catarinense.

Durante o trabalho de campo nas casas das benzedeiras eram frequentes as imagens de santos e santas católicos, além de imagens da crença em divindades locais, tais como São Joao Maria4, dispostos em quadros pendurados na parede da sala, bem como a famosa "aguinha" que é retirada das grutas de água onde o monge São João Maria teria pernoitado no interior do município camponovense. Segundo Welter (2007) a água é um dos elementos fundamentais do mundo joanino para a consagração nos rituais não-eclesiais, que podem ser: "1) pegar água comum e solicitar uma benção de uma autoridade eclesiástica ou, mais frequente, 2) coletar água na fonte de João Maria”.(WELTER, 2007: 72).

Uma das entrevistadas relatou que sempre pede a intercessão de São João Maria para o doente, D. Santina, de origem afro-ítalo-brasileira, contou-me que aprendeu o benzimento tanto com o pai, que era filho de escravos, quanto com a mãe, que era filha de italianos, um sinal do hibridismo descrito por Bhabha (2003: 51) - neste caso, religioso, que se trata de um processo de tradução cultural que nunca se completa, no qual o hibridismo ou as transformações são:

[...] fatos culturais que demarcam a fronteira [e que] podem mudar, e as características culturais de seus membros podem igualmente se transformar apesar de tudo, o fato da contínua dicotomização entre membros e não membros permite-nos especificar a natureza dessa continuidade e investigar a forma e conteúdo da transformação cultural. (BARTH, 1998: 195).

Durante as narrativas das benzedeiras de Campos Novos, verificou-se que elas têm a obrigação e responsabilidade, para com o doente, de estar em cena, presentes, e isso supera o momento dos rituais, perpassando para outros lugares, outros espaços e saberes. No entanto, seus corpos, fisionomias, gestos e suas orações, que perpetuam uma prática que é vista por alguns com maus olhos, ou ainda como sendo ligadas ao supersticioso, foi reprimida pela Igreja Católica, por ser considerada uma prática não vinculada aos seus dogmas, e cujos rituais foram considerados fetichismos, imorais e marcados por uma forte presença diabólica, ideia extremamente difundida pelo catolicismo romanizado5 sobre as práticas não condizentes com a Igreja. Esse conceito influenciou a vida do homem do campo durante os séculos da era cristã. Segundo Azzi (2008: 21-22), "na mentalidade eclesiástica, os verdadeiros

diverso. Nesse sentido a prática de benzimento destas mulheres estão ancoradas entre o local, os saberes locais e os benzimentos, a crença em São João Maria e o global.

4 Monge que percorreu a região do meio-oeste e oeste catarinense no final do XIX e início do século XX. Sua presença foi marcante e significativa no movimento do Contestado. O monge pregava dias melhores aos caboclos e, ao mesmo tempo, dava auxílio aos desamparados, tornando-se assim um homem santo entre a população. Ainda hoje é comum entre as pessoas da região a busca de fontes de água onde supostamente o monge João Maria teria pernoitado. Sobre o assunto ver: BLOEMER, Neusa Maria Sens. Brava gente brasileira: migrantes italianos e caboclos nos campos de Lages. Florianópolis: Cidade Futura, 2000.

5 De forma geral, o Catolicismo Romanizado tinha ênfase no verdadeiro conhecimento das verdades da fé, seguindo os preceitos morais estabelecidos pela Igreja, ou seja, o indivíduo que recebia frequentemente os sacramentos da comunhão e da confissão, além de manter uma vida ascética. Sobre o assunto, ver: AZZI, Riolando. História da Igreja no Brasil: ensaio de interpretação a partir do povo: terceira época: 1930-1964. Petrópolis, RJ: Vozes, $2008: 93$. 
valores do mundo eram aqueles que traziam a conotação espiritual, sobrenatural e religiosa, ao contrário disso são considerados profanos".

Ao indagar sobre a interpretação da Igreja nas práticas de benzimento no município de Campos Novos, em relação ao padre, por exemplo, as entrevistadas relatam diferentes visões: "Tem padre que aceita a minha oração, inclusive eu tirei enxaqueca do padre A., mas tem muitos que não acreditam" (D. Generosa, 86 anos).

De outra benzedeira, temos a informação de que: "Na época de minha mãe não, mas hoje tem uns que aprovam e outros não aprovam, nem sei se eles aceitam. Eu acho que sim, basta ter fé. Tudo depende de ter fé, da fé das pessoas. Tem que ter em Deus em primeiro lugar, né?” (D. Oliva, 62 anos).

Ainda temos outra justificativa: "Os padres não aceitam, é ruim deles aceitarem. Eu sou católica e tenho muita fé em Nossa Senhora Aparecida e Santo Antônio. Aquela ali é minha capelinha, e peço a intercessão de Santo Antônio quando estou benzendo" (D. Santina, 78 anos).

Imagem 1 - Capelinha em frente à casa de Dona Santina, 78 anos. Nossa Senhora Aparecida6, Santo Antônio e outros santos fazem parte do oratório.

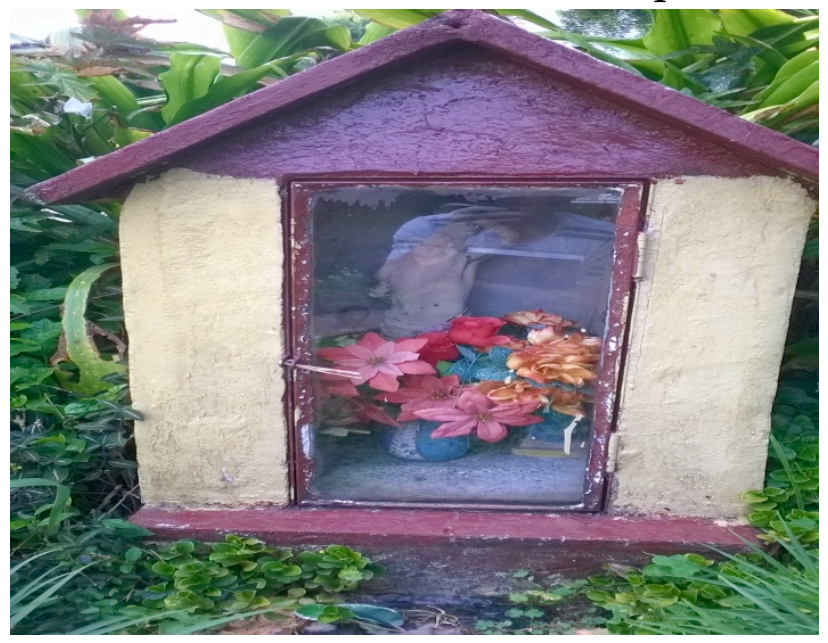

Fonte do autor. Campos Novos - SC

Essas mulheres que viveram no campo, vindas do mundo rural, marcadas pela dominação patriarcal da Igreja nas décadas de 1960 e 1970, pouco representaram à individualidade de suas personagens históricas, devido a forte representação masculina, relevando sua atuação. Corroborando para uma abordagem masculina dos estudos do rural, abordagem geral e por enfocar o mundo do campo como masculino e detentor de representatividade, força e produção. Nos estudos do mundo rural, como os estudos de gênero no mundo rural Woortmann (1985), Woortmann \& Woortmann (1997), o homem é o

6 Nossa Senhora Aparecida é a santa mais milagrosa e mais apreciada entre as entrevistadas. Nas três residências visitadas encontra-se uma imagem em evidência, seja em gesso, em calendários nas paredes ou em imagens pequenas de sortidos materiais. Nossa Senhora Aparecida é a responsável pela maior romaria em sua honra no estado de Santa Catarina. Disponível em: http://camposnovos.sc.gov.br/turismo/item/detalhe/1518. Acesso em o9 de fevereiro de 2017. 
provedor, sendo representado, muitas vezes, como o "racional"; já a mulher é complementação e está relacionada ao emocional e à afetividade.

O benzimento, suas forças, seus mistérios, foram pouco abordados pela historiografia, e, para a Igreja Católica vistos com desconfiança, suspeitas e perigosas, embora a igreja, sobretudo a partir de 1970, após o Concílio Vaticano II, passe a dialogar mais com o povo e suas necessidades, as práticas de benzimento continuaram sendo vistas como práticas contrárias aos dogmas Católicos.

Mulheres camponesas, por estarem diretamente vinculadas à vida do campo e aos deveres morais da religiosidade, certos comportamentos que: "Elas aprendiam desde cedo o que é ser uma boa esposa, uma boa mãe, ou seja, uma boa mulher" (RUBERT, 2014: 74) que determinavam os estilos ideais de agir, e suas condutas morais e estéticas caracterizavam o ideal de viver em comunidade e de ser mulher do campo. O padre, nas regiões rurais do Brasil, teve influência espiritual forte e um controle da fé católica, tanto que nos livros e relatórios enviados à Santa Sé os camponeses eram exaltados pelo bom comportamento.

Conforme Azzi (2008: 92), há "algumas palavras sobre a magnífica reserva religiosa e social que representam às zonas rurais, pelos seus costumes sãos e sua vida simples e religiosa". Significativas parte destas reservas de religiosidade estava construída sobre o papel da família; nesse sentido, a família em contexto rural tinha (e ainda tem) um importante papel na manutenção religiosa, e, a mulher, um papel de guardiã das doutrinas cristãs e na manutenção da ordem. Isso significa que homens e mulheres rurais estavam livres de qualquer interferência urbana e maléfica, no sentido de não se apegarem a outras religiões e ritos profanos. Na percepção da Igreja Católica, as verdadeiras necessidades do homem estavam em sua conotação religiosa e dependência no sentido da espiritualidade. As visões que se tinha desta fé era que os aspectos materiais eram menos importantes; logo, aspectos e crenças do popular eram considerados atos da crendice popular e tratados de forma pejorativa e esnobe.

A representação maternal, bondosa e afetiva da mulher expõe as relações de dominação impregnadas da dominação masculina nas representações do mundo rural e em suas relações sociais. Woortmann (1985) mostra que, nas relações familiares camponesas, a hierarquia está relacionada com as relações de gênero e de papéis, sobretudo nas questões do masculino e de seu poder sobre a relação no sustento familiar e como chefe da organização familiar.

A mulher no mundo rural é a detentora destes saberes, e é responsável pelas práticas do sagrado; é responsável pelos remédios, pelos rituais sagrados e pela sua perpetuação. As mulheres eram as verdadeiras rainhas (principalmente as mulheres camponesas) do lar e a Igreja Católica sabia da importância delas para sua manutenção.

Em relação aos perigos das práticas chamadas profanas pela Igreja Católica, em seu estudo Azzi (2008: 129) complementa: “[...] mães [do campo] de família, senhoras honestas, filhas inocentes e puras, acautelai-vos todas contra o lobo da sotaina, contra as corruptelas imorais que de vós pretendem 
fazer o mais rigoroso instrumento de realização de seus planos tenebrosos". Apesar de toda a preocupação da Igreja Católica, as práticas ainda perduram e são perpetradas com certa frequência. "Aprendi com minha mãe, que era da Itália, "mangia polenta", minha sogra também benzia, eram boas benzedeiras [a sogra e a mãe]" (D. Generosa, 86 anos). A herança do benzimento na maior parte dos casos vem da família, e entre as mulheres da região de Campos Novos esse é um dom e aprendizado feminino: "Eu aprendi de minha madrinha, que eu era afilhada dela, era uma italiana muito católica, e ela não tinha para quem deixar e deixou pra mim.” (D. Oliva, 62 anos).

A decisão de deixar a tradição do benzimento para uma determinada pessoa não é aleatória: são na sua maioria, mulheres, essas mulheres precisam ter uma boa representatividade na comunidade local, ter contato e convívio com a esfera do sagrado, porém, não apenas o aspecto religioso, mas permeando as relações familiares, sociais e culturais da localidade.

Ainda há nesses legados um significado étnico que é passado de geração para geração, as entrevistadas fazem questão de explicitar a origem do aprendizado e de quem aprenderam; tais legados fazem parte do cotidiano destas mulheres, que desempenham o papel de unir o começo e o fim - é mais que uma rememoração é nostalgia, é uma função de ser ainda útil, de exercer ainda uma função social, de mostrar sua importância para a comunidade local. Conforme Bosi (2003: 55), "não é sonho, é trabalho", já que as experiências dessas mulheres são elaboradas a partir de situações concretas As lembranças se constituem no trabalho cotidiano das ferramentas de benzimento, bem como de suas representações e imaginários sociais, e ainda se referem às heranças do benzimento. Ginzburg (1998: 126) esclarece que:

São crenças que aprendem na primeira infância, geralmente de suas mães depositárias dessas heranças de tradições; assim se explica que no momento em que estes se afastam das aldeias de origem, às vezes contra sua vontade, essas crenças se transformam em um vínculo muito forte que liga e reúne os migrantes.

Durante o trabalho de campo realizado na cidade de Campos Novos, segundo semestre de 2014, pôde-se perceber esses aspectos da representação do outro, dos imaginários, e até de um poder que excede o espiritual e relaciona-se com a mística do catolicismo. Assim, a benzedeira tem um papel que é fundamental nesse processo. Na casa de D. Oliva, 62 anos, uma mãe leva seu filho de 7 anos para benzer das "bichas" (Figura 2). Ela relata que: "Sempre que meu filho está nervoso, e não dorme direito, eu trago para D. Oliva benzer. Ele volta para casa muito melhor. Eu sempre trago meus filhos aqui, e indico também para conhecidas, ela é uma benzedeira de mão cheia." (Mãe do menino, out. de 2014).

Desta forma, o indivíduo que procura uma benzedeira se utiliza do espaço de experiência anteriormente, e o que se espera é que tal realidade passada, e neste caso já utilizada no passado, continue trazendo resultado no futuro, ou, no dizer de Koselleck (2006), em um horizonte de expectativa, que pode ser concretizado ou não, mas é esperado. 
Acompanhei o ritual de benzimento de um menino na casa de D. Oliva, para o ritual do benzimento de um menino de 7 anos, D. Oliva convida a mãe do menino para entrar na cozinha de sua casa, acomoda o menino em uma cadeira e lhe pergunta o que sente: "Ele tá muito nervoso, não dormiu direito essa noite!" [Resposta da mãe do menino, out. de 2014].

D. Oliva transforma-se, torna-se séria e concentra-se no benzimento e afetando quem a observa e quem recebe o benzimento.

Segundo Bhabha (2003: 212), "[o olhar] etnográfico demanda que o próprio observador seja uma parte de sua observação e isto requer que o campo de conhecimento - o fato total - [seja] como uma coisa que inclui dentro de si a compreensão subjetiva do nativo [...]". É como uma passagem de um lugar para o outro, seu habitus corporal muda, seu campo energético, seu tom de voz, seus gestos, o menino a ser benzido também não fala e, após, vem o relato da mãe do menino sobre o problema, D. Oliva utiliza suas ferramentas, faz o sinal da cruz e inicia o benzimento com orações católicas:

Pai nosso que estai no céu, santificado seja o vosso nome, venha a nós o vosso reino assim na terra como no céu; o pão nosso de cada dia nos dai hoje, perdoai a nossa ofensa assim como nós perdoamos a quem tenha lhe ofendido e não deixei cair em tentação, mais livrai ele do mal. Amém. (D. Oliva, 62 anos).

D. Oliva termina a oração, e tem início o ritual de benzimento da criança, com uma linha7 e com uma oração católica:

Ave Maria cheia de graça, o senhor é convosco, bendita sois vós entre as mulheres e bendito é o fruto do vosso ventre, Jesus. Santa Maria, mãe de Deus, rogai por nós, Nossa Senhora Aparecida. Rogai por nós, pecadores, agora e na hora da nossa morte. Amém. (D. Oliva, 62 anos).

Imagem 2 - D. Oliva, 62 anos, benzendo das "bichas8”.

7 A linha de costura, neste caso, tem a função de representar simbolicamente as bichas, ou os vermes, e após o benzimento essa linha é cortada em vários pedaços. No Filme A árvore dos Tamancos, de Ermanno Olmi, de 1978, que retrata a vida de camponeses pobres do norte da Itália no final do século XIX, o diretor evidencia situações de práticas de benzimento do período naquele país. A partir de 2h:05 min. do filme é possível verificar uma cena semelhante ao benzimento que é feito por D. Oliva, que aprendeu de sua madrinha, que era italiana. Ainda, o uso da linha para benzer é descrito no livro de Joana Bahia, entre as descendentes pomeranas no estado do Espírito Santo (BAHIA, Joana. O tiro da bruxa: identidade, magia e religião na imigração alemã. Rio de Janeiro, Garamond, 2011).

8 Bichas, no linguajar da benzedeira, é quando uma criança está com vermes. D. Oliva conta que uma criança pode ter vermes, ou bicha, quando privada de algum alimento ou quando come muito, ou ainda quando se assusta à noite, segundo ela as bichas ficam mexidas. 


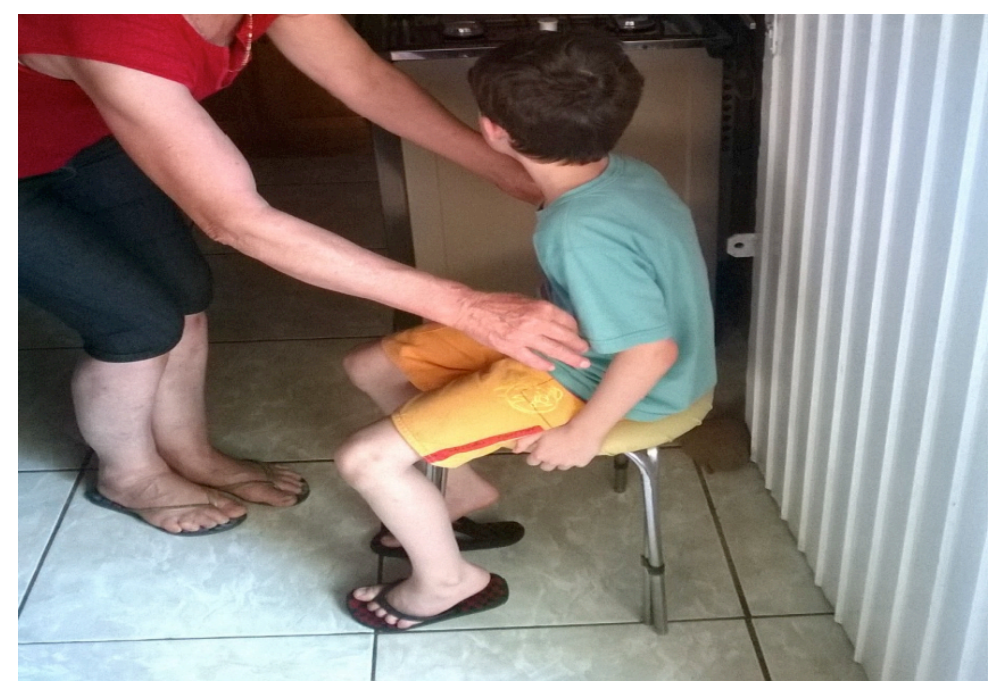

Fonte do autor. Campos Novos -SC

Terminada esta primeira etapa, D. Oliva corta a linha dentro de um copo com água que estava em frente à imagem de Nossa Senhora Aparecida. E durante o processo continua em silencio e concentrada na ação de cortar a linha.

Imagem 3 - D. Oliva, 62 anos, cortando a linha (as bichas).

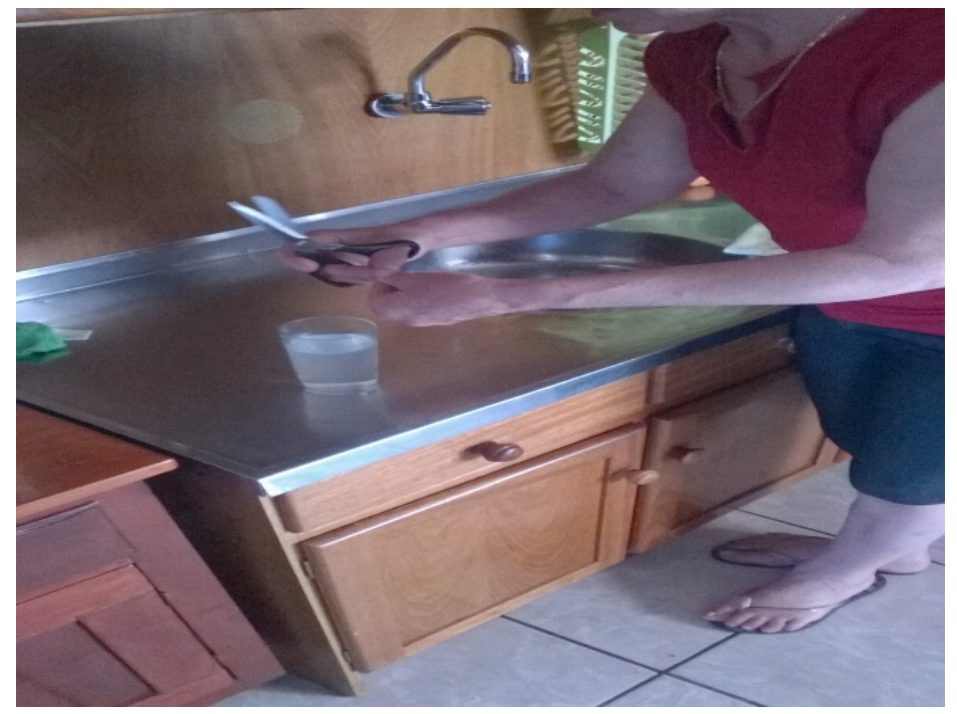

Fonte do autor. Campos Novos -SC

No momento do ritual da reza, as palavras são poesia, há riquezas em suas entonações, suas corporeidades se transformam em gestos, mas também são ferramentas que agem sobre a doença e/ou sobre o mal que acomete o doente. A prece, neste sentido, tem um discurso sobre o ouvinte e, consequentemente, sobre o social. E é a partir da estrutura do ritual, da palavra, dos atos da fala, que estamos aptos a contar o ocorrido.

Após o ritual, ela oferece a água para a criança beber, faz o sinal da cruz e ergue o copo em direção da luz; dessa forma ela dá seu diagnóstico: 
Eu benzo das bichas, vermes e quebranteg somente crianças. Mau olhado, né, mas sempre com copo de água e uma linha meço na cabeça e até no umbigo, daí faço uma cruz nos braço [sic], primeiro com a linha simples, depois eu faço mais duas cruz com a linha dupla e depois mais três cruz com linha dupla de novo, daí eu corto [as bichas] a linha dentro de um copo com água, daí eu peço o nome da criança, daí eu digo o que eu corto, eu mesmo falo, por que as veiz [sic] a criança não fala, não sabe, daí eu falo:

- O que que eu corto?

- Bicha braba.

Daí eu rezo um Pai Nosso, uma Ave Maria e um Santo Anjo, e daí dou a água para a criança tomar três vezes né, três golinhos, se a linha ficar embolada, tudo junto a criança tá mexida, tem bicha, e se não tiver a linha fica tudo espalhadinha. (D. Oliva, 62 anos).

Há uma intermediação entre o santo e as pessoas a serem benzidas. A benzedeira possui a especialidade para as rezas e o santo da intercessão da cura. A benzedeira se reveste de certas práticas mágicas que auxiliarão na cura do doente. Por isso, auxiliam aqueles que necessitam de ajuda sem pedir auxílio financeiro. Entre as entrevistadas é unânime a ideia de que quem possui o dom de benzer não pode cobrar nada em troca, isto é, benefícios em dinheiro e/ou qualquer outro lucro a partir da especialidade divina que cada uma possui:

\begin{abstract}
Nunca cobrei, nunca, é difícil eles deixar alguma coisa, um presentinho a gente aceita de bom grado, mas eu não cobro nada, nunca. Porque eu acho que isso é um Dom de Deus, não é todo mundo que pode benzer, tem que ter muita fé e eu tenho muita fé, tanto que eu recebo bastante gente aí, bastante criança, quase todo dia vem gente, elas ficam muito agradecidas, as mães falam que elas [as crianças] melhoram e ficam calmas, eu sempre tenho chá de hortelã na frente da casa e na horta e recomendo para elas [mães] dar, né, chá de hortelã ou erva-doce1o. Há muito tempo que eu faço isso. (D. Oliva, 62 anos).
\end{abstract}

As relações de "contratos" entre as benzedeiras com o sagrado são apenas de valor humanitário, ou seja, a benzedeira possui o dom de benzer, é sua obrigação fazer o bem à comunidade. No sentido de Mauss (1974), é uma dádiva, e não uma troca de moedas, através destes significados simbólicos do benzimento, assim o benzer é reconhecido porque atua na comunidade local. Isso assegura uma relação harmônica e afetuosa com a comunidade, e de divulgação do nome da benzedeira para outras pessoas.

A tradição do benzimento para essas mulheres supera questões habituais ou de determinada tradição, pois traz para o presente astucias e resistências que o poder do dom pode lhes proporcionar: apesar de não trazer benefícios financeiros, elas têm um poder de autoridade sobre o assunto; fazer o bem ao doente e sua família é a missão, por isso a comunidade precisa partilhar e compartilhar desse dom. O sagrado se manifesta na linguagem, e exprime ingenuamente o mistério da fascinação e ao mesmo tempo do respeito de uma detentora do saber local. A benzedeira é alguém que conhece a comunidade e as pessoas, sendo que suas práticas, que parecem vir de um passado distante e de poucas possiblidades médicas, persistem em práticas de cooperação, solidariedade e ajuda mútua no presente.

9 Quebrante é o mau-olhado sobre a criança e somente uma benzedeira pode tirar o mal que lhe foi feito através de suas orações.

10 Sobre a erva-doce e a hortelã, D. Oliva conta que faz bem dar para a criança que está com quebranto, pois acalma a criança. Pensando nos estudos de Ginzburg (1988), os ramos de erva-doce eram usados para combater o mal, ou a pessoa que estava com mau-olhado. Nos estudos de Bahia (2011) sobre a magia entre as pomeranas do Espirito Santo, também é possível obter uma referência sobre os chás e as plantas para afugentar o mau-olhado. 
O dom de benzer pode ser adquirido, mas para seguir nessa missão precisa-se do dom natural, fazendo com que esse dádiva circule em prol dos outros, em prol da solidariedade para com a comunidade.

\section{É um dom e nem todo mundo pode benzer, tem que ter fé. Eu passei para minha filha, mas ela não quer; tem que praticar e tem que ter o dom, né, senão não adianta. Também não cobro, é pecado; se a pessoa quiser deixar um presentinho11, aceito, mas não pode cobrar, é um dom isso. (D. Santina, 78 anos).}

A cultura popular, bem como o catolicismo popular, é um conjunto de práticas das camadas subalternas - o que Certeau (1994) utilizou para descrever as práticas cotidianas dos indivíduos dominados. No caso das mulheres da área rural, camponesas com uma condição financeira desfavorecida, com pouca escolaridade, ocasionada muitas vezes pela dominação masculina e imposição da família e pela herança cultural do grupo, com poucas condições de tratamento médico, elas "(re)inventam seu cotidiano" e partem para uma medicina alternativa. Quem tinha o dom de benzer era o padre, e não os homens "comuns", que não possuíam autoridade espiritual, prática moral e religiosa para tal ato; a palavra do padre, como em assuntos profanos, se tornava decisiva. A bênção do padre se dava sobre as pessoas doentes, para o plantio e uma boa colheita, para os animais, para as crianças, para os lares e objetos específicos e para as vestimentas. As práticas da Igreja Católica contra o benzimento visavam garantir, também, a sua forte presença e autoridade espiritual sobre a população, principalmente sobre os indivíduos do campo, bem como manter a fé genuína dos camponeses, que de certa forma criavam métodos para continuar com suas ações, fato que hoje ainda se efetiva no cotidiano:

Faz muito tempo que eu benzo, 50 anos já, desde nova. Tem gente que agradece, outros não, mas não pode pagar, é um dom e a gente tem que fazer o bem, eles sempre estão agradecendo, dizem: Nona foi uma maravilha!, ontem a senhora me benzeu e sarei, nona foi isso e aquilo... É um dom, pelo amor de Deus, é coisa séria, poucas pessoas podem benzer. (D. Generosa, 86 anos).

Imagem 4 - Sala de D. Generosa, local onde costuma benzer, detalhe para as imagens de santos na parede.

11 Em seu Ensaio sobre a Dádiva na Polinésia, Marcel Mauss (1974) descreve os rituais de trocas, ou favores, descritos no seu trabalho etnográfico como "potlatch", que são presentes ou favores retribuídos ao bem feito pelo outro - uma forma de agradecer pelo trabalho realizado. 


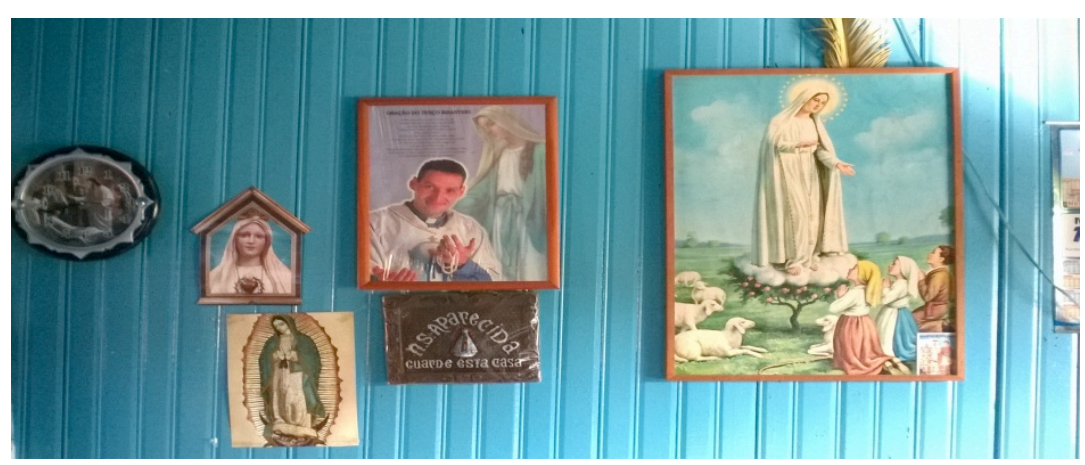

Fonte do autor. Campos Novos - SC.

A benzedeira precisa ser alguém em quem a comunidade confie; assim, no dizer de D. Generosa, benzer é coisa séria, não é para qualquer um(a). Nesse sentido, a benzedeira é alguém que expresse sua religiosidade, sua fé no ato de benzer e, principalmente, que a comunidade reconheça nela alguém capacitada para a "tarefa" do benzimento. Mauss (1974) expõe que a magia é um símbolo de elo do qual a coletividade usufrui e que faz parte de seu contexto social e cultural.

D. Generosa é conhecida por toda a comunidade como uma boa benzedeira, criando redes sociais entre a vizinhança, cumplicidade e respeito. Ela conta como benze e o seu cotidiano com o benzimento:

Eu benzo da cabeça, de enxaqueca e mal-estar, com uma garrafa cheia de água, um pano na cabeça do lado do sol, né, por que daí o sol puxa o que tem de ruim, a dor e o mal-estar. Aí rezo Pai Nosso, Glória e Ave Maria, e peço intercessão de Nossa Senhora Aparecida. Sempre tem um homem e uma mulher aqui em casa para benzer. Às vezes tô [sic] aqui dentro e me chamam: Nona, vem me benzer!! [risos]. (D. Generosa, 82 anos).

Imagem 5 - Altar em que D. Generosa costuma deixar a “água para Nossa Senhora Abençoar”.

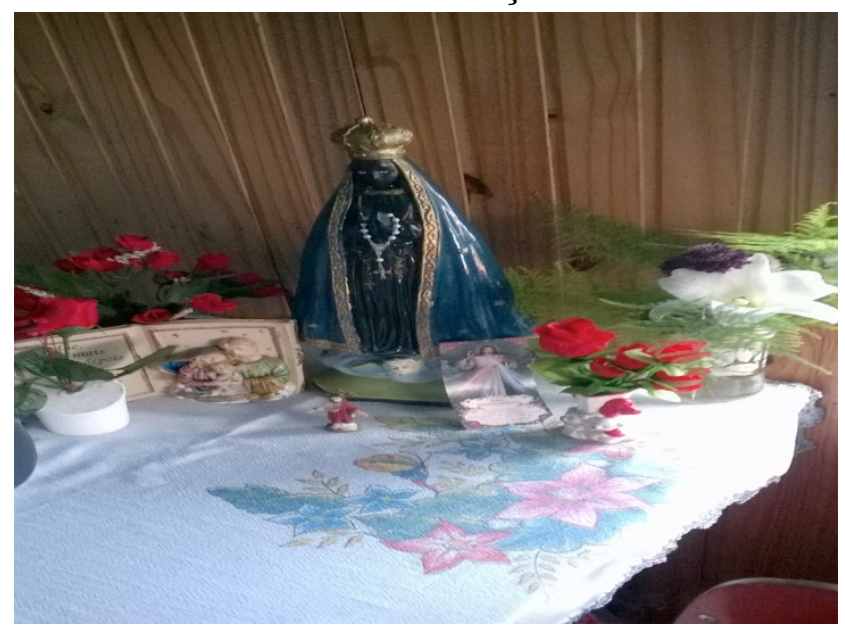

Fonte do autor. Campos Novos - SC

O dom que D. Generosa possui é um privilégio usufruído pela comunidade, e que lhe confere um status, poder de (re)conhecimento sobre o assunto a ser tratado, mas ao mesmo tempo uma responsabilidade que impõe a D. Generosa e 
a outras benzedeiras obrigações de fazer o bem. Elas continuam trabalhando por uma medicina espiritual e, consequentemente, mais acessível financeiramente às famílias que delas buscam a cura.

\begin{abstract}
Eu benzo de rendidura12 nas costas, né, de cobreiro, faz muitos anos que faço isso, 34 anos já, coloco uma lata de água quente dentro do prato e depois coloco nas costas da pessoa, ou em cima das pernas se for rendidura das pernas, aí eu digo: $O$ que eu cozô? A pessoa tem que dizer, né, ai eu digo: Osso quebrado, nervo rendido e carne rasgada13. Se for cobreiro: O que que eu corto? Aí a pessoas diz: cobreiro brabo! E eu digo: Cobreiro brabo, te corto, te furo e te fujo. Tem gente que eu nem digo em voz alta porque dá risada, aí eu nem falo, só em pensamento. Antigamente se tinha mais fé. (D. Santina, 78 anos).
\end{abstract}

Como já apontado, a palavra proferida pela benzedeira tem forte poder no momento do benzer e da cura do mal que acomete o paciente; ao pronunciar as palavras ou a fórmula "te corto, te furo e te fujo", a benzedeira utiliza seu poder mágico de cortar, furar o cobreiro e afugentá-lo. Todo esse ritual de entonações e palavras é permeado de simbologia; os gestos, as pessoas, as casas das benzedeiras e, claro, as próprias benzedeiras: o benzer é carregado de rituais que não somente dizem o que querem, mas também fazem algo, tocam e de certa forma toca o paciente. Nesse sentido, as fotografias aqui utilizadas para ilustrar fazem uma leitura visual do que foi explicado pela benzedeira, fazendo parte da etnografia e contribuindo para os rituais do benzer, essas imagens são artefatos valiosos para o etnógrafo. Essas imagens são portadoras da qualidade da informação e da emoção, de suas expressões corporais, seus gestos, uma mão que benze, uma imagem de santo. Neste trabalho, as imagens aparecem como interpretações de um universo simbólico ainda pouco estudado na cidade, em permanentes transformações de identidade em um universo invisibilizado.

$\mathrm{Na}$ comunidade onde se desenvolveu a pesquisa em 2014 é possível averiguar uma predominância maior de ítalo-brasileiros, mas também uma significativa população de afro-brasileiros. O que quero dizer com isso é que há um hibridismo cultural presente, onde não há hierarquias de saberes entre a comunidade ítalo-brasileira ou afro-brasileira e essas identidades não são tão rígidas quanto possam parecer.

As benzedeiras, tanto de origem afro quanto ítalo, pareciam híbridas, no sentido de Bhabha (2003); é uma mistura que vem de combinações de seres humanos e bricolagem étnica. As benzedeiras trocam benzimentos entre si e não há uma hierarquia: se há um paciente que precisa de certo tipo de benzimento, é recomendado a determinada especialista, que benze de rendidura, enxaqueca, vermes, entre outros males. Se, por um lado, estas mulheres estão inseridas em um contexto de constantes mudanças e, seus saberes e fazeres são parte de uma diáspora migratória, mas que resultam em processos de reproduzir e reinventar seus fazeres de benzer, que são manifestações que ocorrem no presente, mas com conhecimentos que estão pautados em uma longa caminhada histórica preenchida com saberes e fazeres étnicos locais. Se para alguns o termo

12 Rendidura é quando o indivíduo se machuca e acaba atrofiando algum membro do corpo, como pernas, o braço ou as costas.

13 Rasgadura é semelhante à rendidura, só que, neste caso, o indivíduo rasga a carne ou a pele, com uma queda ou um objeto cortante. Ainda segundo as benzedeiras, as rasgaduras podem ser internas - neste caso há uma recomendação de ervas medicinais: a babosa é recomendada nestes casos, pois, segundo as benzedeiras, ela tem um efeito antibiótico. 
"benzedeira" é algo que ficou no passado, para as mulheres que benzem em Campos Novos - e para quem a utilizam no presente - é uma atividade cotidiana.

A prática do benzimento segue persistindo, mas há dúvidas quanto a seu futuro. Durante o trabalho de campo, questionei as benzedeiras sobre para quem gostariam de deixar essa tradição, embora, conforme Koselleck (2006), as coisas podem acontecer diferentemente do que se espera ou se imagina sobre determinado assunto. Neste nesse sentido, o horizonte de expectativa dessa prática é uma incógnita:

\begin{abstract}
A minha filha, eu passei para ela, mas ela não quer dizer para ninguém que benze, porque é um compromisso, eles até fazem de pouco, acham graça! (D. Generosa, 86 anos).
\end{abstract}

Não tem, hoje em dia; ninguém mais qué [sic]. Mas eu gostaria de deixar essa tradição para minha filha, mas eu acho que não vai querer! (D. Oliva, 62 anos).

Eu passei para minha filha, mas ela não quer, tem que praticar e tem que ter o dom, né, senão não adianta! (D. Santina, 78 anos).

A prática do benzimento pode ser adquirido, mas a escolha da benzedeira precisa ser estabelecido a partir dos padrões estabelecidos pelo grupo, como sendo uma 'boa benzedeira', elencando valores como responsabilidade, religiosidade, e ainda conforme as benzedeiras, o dom.

O riso sobre o benzimento, comentado por D. Generosa, coloca esta mulher entre dois mundos, ou melhor, entre duas épocas - entre estar aqui, no presente, e estar lá, no passado. D. Generosa e as outras benzedeiras não são excepcionais e não são detentoras exclusivas de saberes medicinais do passado; elas são do presente e fazem uso de práticas do passado ainda no presente. Segundo Lévi-Strauss (1975) a cura depende de três fatores da crença na magia, isto é, da crença da benzedeira e na sua técnica do benzer pelo paciente, a crença da própria benzedeira em sua técnica e por fim do grupo de pessoas ou da comunidade que utiliza das práticas de benzimento. Como a jovem mãe que leva seu filho ao benzimento acreditando nas práticas da benzedeira no ano de 2014 . $\mathrm{O}$ autor que escreve este texto também foi levado pela sua mãe em meados da década de 1990 para o benzimento, onde o universo da cura continua sendo praticado.

Partindo desse pressuposto das identidades na pós-modernidade (Hall, 2006), segundo o qual a globalização cria novas identidades e novas tradições, renegando as velhas:

Quanto mais a vida social se torna mediada pelo mercado global de estilos, lugares e imagens, pelas viagens internacionais, pelos sistemas das mídias e pelos sistemas de comunicação globalmente interligados, mais as identidades se tornam desvinculadas - desalojadas - de tempos, lugares, histórias, e tradições específicos parecem flutuar livremente. (HALL, 2006: 75).

Concluindo, suas práticas de cura estão repletas de bons significados e de simbologias, significados estes questionados pela Igreja Católica durante vários momentos da história e confundidos com práticas demonizadas. Estas mulheres do campo, protagonistas de suas histórias, continuam enquanto há forças e quem as procure. Essas práticas continuam sendo utilizadas pela população. 
Conforme descrito por Koselleck (2006), a experiência e a expectativa são ocupações da história, pois elas "entrelaçam passado e futuro".

Sendo assim, os caminhos da pesquisa com benzimentos e mulheres benzedeiras são fartos e as possibilidades também; uma continuidade da análise deste campo de estudos seria um trabalho de maior aprofundamento etnográfico - utilizando as memórias e histórias de vida destas mulheres e de tantas outras camponovenses que benzem - a fim de perceber como essas mudanças e transformações na religiosidade e realidade brasileira contemporânea vêm alterando significados e mantendo rituais que, em uma sociedade globalizada, parecem ser histórias de um mundo distante esquecido no passado.

\section{Fontes das Imagens}

Figura 1 - Capelinha em frente à casa de Dona Santina, Nossa Senhora Aparecida, Santo Antônio e outros santos. Fonte do autor. 20/10/2014.

Figura 2 - D. Oliva, benzendo das "bichas". Fonte do autor. 25/10/2014.

Figura 3 - D. Oliva, cortando a linha. Fonte do autor. 25/10/2014.

Figura 4 - Quadros de santos, local onde costuma benzer. Fonte do autor. $20 / 10 / 2014$.

Figura 5 - Altar em que D. Generosa. Fonte do autor. 25/10/2014.

\section{Referências Bibliográficas}

AZZI, Riolando; GRIJP, Klaus Van Der. História da Igreja no Brasil: ensaio de interpretação a partir do povo. Petrópolis: Vozes, v. 2, p. 1.930-1.964, 2008.

BAHIA, Joana. O tiro da bruxa: identidade, magia e religião na imigração alemã. Rio de Janeiro: Garamond, 2011.

BARTH, Fredrik; STREIFF-FENART, Jocelyne; POUTIGNAT, Philiphe. Teorias da etnicidade. São Paulo: Editora da Unesp, 1998.

BHABHA, Homi. K. O local da cultura. 2. ed. Belo Horizonte: UFMG, 2003.

BLOEMER, Neusa Maria Sens. Brava gente brasileira: migrantes italianos e caboclos nos campos de Lages. Florianópolis: Cidade Futura, 2000.

BOSI, Ecléia. O tempo vivo da memória: ensaios de psicologia social. São Paulo: Ateliê, 2003. 
CASCAES, Franklin. O fantástico na ilha de Santa Catarina. Volume I. $5^{\mathrm{a}}$ ed. Florianópolis: Ed. da UFSC, 2003.

CERTEAU, Michel de. A invenção do cotidiano. Petrópolis, RJ: Ed. Vozes, 1994.

DIAS, Maria Odila Silva. Hermenêutica do quotidiano na historiografia contemporânea. Revista do Programa de Estudos Pós-Graduandos de História da PUC-SP, v. 17, n. 2, p. 223-258, nov. Projeto História, 1998.

GELESKI, Fátima. Benzedeiras na Ilha de Santa Catarina a partir da perspectiva de Oswaldo Rodrigues Cabral. Revista Santa Catarina em História, v. 8, n. 1, p. 150-160, 2014.

GINZBURG, Carlo. Os andarilhos do bem: feitiçaria e cultos agrários nos séculos XVI e XVII. São Paulo: Companhia das Letras, 1998.

HALBWACHS, Maurice; SIDOU, Beatriz. A memória coletiva. São Paulo: Centauro, 1990.

HALL, Stuart. A identidade cultural na pós-modernidade. 11. ed. Rio de Janeiro: DP\&A.[1. ed.: 1992], 2006.

UFMG, 2006.

Da diáspora: identidades e mediações culturais. Belo Horizonte:

KOSELLECK, Reinhart. Futuro passado: contribuição à semântica dos tempos históricos. Rio de Janeiro: PUC/RJ, Contraponto, 2006.

MAUSS, Marcel. Ensaio sobre a dádiva: forma e razão da troca em sociedades arcaicas. In: Sociologia e antropologia. São Paulo: EPU, v. 2, 1974.

MALUF, Sônia Weidner. Encontros noturnos: bruxas e bruxarias na Lagoa da Conceição. Rio de Janeiro Editora Rosa dos Tempos, 1993.

RENK, Arlene. Sociodicéia às avessas. Chapecó-SC: Editora Grifos, 2000.

RUBERT, Gabriela. Cristina Maceda. A construção do sagrado: benzedeiras $e$ práticas religiosas em Cambé/Paraná. 129f. Dissertação (Mestrado em História) Departamento de História - UEL, Londrina/PR, 2014.

LÉVI-SRAUSS, Claude. O feiticeiro e sua magia. In. Antropologia estrutural. Rio de Janeiro, Tempo Brasileiro, 1975.

TEIXEIRA, Faustino. Faces do catolicismo brasileiro contemporâneo. Revista $U S P$, n. 67, p. 14-23, set./nov, 2005.

WELTER, Tânia. O Profeta São João Maria continua encantando no meio do povo: Um estudo sobre os discursos contemporâneos a respeito de João Maria em Santa Catarina. 338 f. Tese (Doutorado em Antropologia) Departamento de Antropologia - UFSC, Florianópolis, 2007.

WOORTMANN, Klass. A comida, a família e a construção do gênero feminino. Dados: v. 29, n. 1, p. 103-130, 1985. 
WOORTMANN, Ellen. F., WOORTMANN, Klass. O Trabalho da Terra: A lógica e a simbólica da lavoura camponesa. Brasília: EdUNB, 1997.

Recebido em 09/03/2017. Aprovado em 17/04/2017. 